\title{
In vitro fermented nuts exhibit chemopreventive effects in HT29 colon cancer cells
}

\author{
Stefanie Lux ${ }^{1}$, Daniel Scharlau ${ }^{1}$, Wiebke Schlörmann ${ }^{2}$, Marc Birringer ${ }^{3}$ and Michael Glei ${ }^{1 *}$ \\ ${ }^{1}$ Department of Nutritional Toxicology, Institute of Nutrition, Friedrich-Schiller-University Jena, Dornburger Strasse 24, \\ 07743 Jena, Germany \\ ${ }^{2}$ Department of Nutritional Physiology, Institute of Nutrition, Friedrich-Schiller-University Jena, Dornburger Strasse 24, \\ 07743 Jena, Germany \\ ${ }^{3}$ Department of Nutritional, Food and Consumer Studies, University of Applied Science Fulda, Marquardstrasse 35, \\ 36039 Fulda, Germany
}

(Submitted 20 April 2011 - Final revision received 1 November 2011 - Accepted 2 November 2011 - First published online 15 December 2011)

\section{Abstract}

It is proven that nuts contain essential macro- and micronutrients, e.g. fatty acids, vitamins and dietary fibre (DF). Fermentation of DF by the gut microflora results in the formation of SCFA which are recognised for their chemopreventive potential, especially by influencing cell growth. However, little is known about cellular response to complex fermentation samples of nuts. Therefore, we prepared and analysed (pH, SCFA, bile acids, tocopherol, antioxidant capacity) fermentation supernatant (fs) fractions of nuts (almonds, macadamias, hazelnuts, pistachios, walnuts) after in vitro fermentation and determined their effects on growth of HT29 cells as well as their genotoxic/anti-genotoxic potential. The fermented nut samples contained 2- to 3-fold higher amounts of SCFA than the faeces control, but considerable reduced levels of bile acids. While most of the investigated native nuts comprised relatively high amounts of tocopherol $(\alpha$-tocopherol in almonds and hazelnuts and $\gamma$ - and $\delta$-tocopherol in pistachios and walnuts), rather low concentrations were found in the fs. All nut extracts and nut fs showed a strong antioxidant potential. Furthermore, all fs, except the fs pistachio, reduced growth of HT29 cells significantly. DNA damage induced by $\mathrm{H}_{2} \mathrm{O}_{2}$ was significantly reduced by the fs of walnuts after 15 min co-incubation of HT29 cells. In conclusion, this is the first study which presents the chemopreventive effects (reduction of tumour-promoting desoxycholic acid, rise in chemopreventive SCFA, protection against oxidative stress) of different nuts after in vitro digestion and fermentation, and shows the potential importance of nuts in the prevention of colon cancer.

\section{Key words: Nuts: In vitro fermentation: Dietary fibre: Human colon cells: Cell growth: Antioxidant capacity}

Traditionally, nuts have been considered to be unhealthy because of their high content of fat ${ }^{(1,2)}$. However, recent findings attribute a wide range of health benefits resulting from nut consumption. Nuts are an important source of essential macro- and micronutrients, e.g. fatty acids, vitamins and minerals. In addition, some species provide $10 \%$ of the recommended daily intake of thiamine, niacin, $\mathrm{P}$ and $\mathrm{Zn}$ under allowance of the daily intake of $40 \mathrm{~g}$ nuts a day, according to the US Department of Agriculture ${ }^{(1)}$. Furthermore, nuts contain polyphenols and carotenoids which also have health-improving effects ${ }^{(3,4)}$. Evidence exists that an increased consumption of nuts can protect from $\mathrm{CVD}^{(5)}$ and $\mathrm{Hu}$ et al. demonstrated that death from heart disease as well as nonlethal heart attacks can be reduced. These effects are probably a cause of the lipid profile of nuts, because they contain mainly MUFA and PUFA which can reduce the levels of
LDL-cholesterol $^{(6)}$. Different studies demonstrated that the protection against CVD is at least partly caused by the modulation of serum lipids through unsaturated fatty acids. The consumption of only four walnuts a day over 3 weeks (in addition to the regular diet), e.g. significantly increased blood levels of $\alpha$-linoleic acid and its metabolite eicosapentaenoic acid ${ }^{(7-9)}$ In addition, Torabian et al. ${ }^{(10)}$ demonstrated that including walnuts as part of a habitual diet (free-living situation) also favourably altered the plasma lipid profile. Importantly, no additional weight gain was observed in human studies with nuts $^{(11-13)}$. Nuts are also rich in different tocopherol forms and can deliver more than $20 \%$ of the recommended daily allowance $^{(14)}$. It is notable that different nuts contain divergent tocopherol profiles. For example, hazelnuts and almonds are the best source for $\alpha$-tocopherol $(15 \mathrm{mg} / 100 \mathrm{~g}$ and $16 \mathrm{mg}$ / $100 \mathrm{~g}$ ), pistachios and walnuts contain mainly $\gamma$-tocopherol

Abbreviations: ABTS, 2,2'-azino-bis(3-ethylbenzothiazoline-6-sulfonic acid); BA, bile acids; DAPI, 4',6-diamidino-2-phenylindol; DCA, desoxycholic acid; DF, dietary fibre; DPPH, 1,1-diphenyl-2-picrylhydrazyl; fs, fermentation supernatants; TEAC, trolox equivalent antioxidant capacity.

*Corresponding author: Professor M. Glei, fax + 4936419496 72, email michael.glei@uni-jena.de 
$(22 \mathrm{mg} / 100 \mathrm{~g} \text { and } 21 \mathrm{mg} / 100 \mathrm{~g})^{(15,16)}$. Nuts are also an excellent source of health-promoting dietary fibre (DF). They can deliver between 5 and $12 \%$ of the recommended daily intake $(30 \mathrm{~g})$ of $\mathrm{DF}^{(4,17,18)}$. This is highly interesting because of the beneficial effects of DF on the digestive tract, especially the large intestine. DF absorb water and thus increase stool bulk and prevent obstipation ${ }^{(19)}$. The beneficial effects also include the reduction of symptoms caused by chronic inflammatory bowel disease and chemoprevention of colorectal cancer ${ }^{(20)}$. Reports of Davis \& Iwahashi ${ }^{(21)}$ suggest that nuts can be considered to be a protective factor of the colon. Whole-almond fractions reduced incidences of histological alterations of the colon mucosa of rats. Results of the European Prospective Investigation into Cancer and Nutrition study with 36994 subjects in ten different countries demonstrated an inverse association between consumption of nuts and seeds and the risk of colorectal cancer in women ${ }^{(22)}$. DF do not only increase stool bulk, they can also increase the amounts of SCFA, like butyrate, propionate and acetate in the lumen of the colon ${ }^{(23)}$. Butyrate and, to a minor extent, propionate have been shown to inhibit the growth of colon tumour cells, by blocking proliferation and initiating apoptosis ${ }^{(24,25)}$. In contrast, butyrate and other metabolites of DF fermentation act as growth factors in non-transformed colon cells and can increase the toxicological defence systems ${ }^{(26,27)}$. Selected DF, termed prebiotic fibre, increases the amounts of SCFA in the colon and stimulates the growth of beneficial lactic acidproducing bacteria ${ }^{(28-30)}$. Especially bifidobacteria can improve colonic health by lowering the $\mathrm{pH}$-value in the colonic lumen, thereby inhibiting the growth of pathogenic bacteria ${ }^{(31,32)}$. Furthermore, prebiotics are able to reduce the genotoxic potential of faecal water and thus reduce the exposure of the colon epithelium with potential carcinogens ${ }^{(33-35)}$. Up till now, the effects of nuts on colonic health have not been well analysed and little is known about the metabolites which are formed during their fermentation. Considering that colorectal cancer is one of the most frequent and deadly cancer forms worldwide ${ }^{(36)}$, studying these effects may increase the knowledge on the health benefits of nuts, next to their role in the prevention of CVD. Therefore, we generated fermentation supernatants (fs) of five different nut species (almonds, macadamias, hazelnuts, pistachios and walnuts) by using an in vitro fermentation system simulating the human digestion ${ }^{(25,37,38)}$. The first goal of the present work was to characterise and to compare the fermentation products of different nuts regarding concentrations of SCFA (acetate, propionate and butyrate), tocopherols, antioxidant capacity and bile acids (BA). HT29 colon adenocarcinoma cells were treated with these fs and the effects on cell growth, cell cycle modulation as well as the genotoxic/anti-genotoxic potential of the fs were studied.

\section{Material and methods}

\section{In vitro fermentation of nuts}

The five different nut varieties used in this study were delivered from Blue Diamond Growers (almonds), Max Kiene
GmbH (macadamias), Turkish Hazelnut Promotion Group (hazelnuts), Paramount Farms (pistachios) and Mariani Nut Company (walnuts). The nuts were digested using an in vitro simulation of the human gastrointestinal passage according to a previously described protocol ${ }^{(38-40)}$. In brief, $2 \mathrm{~g}$ of each nut variety were ground and suspended in anaerobic potassium phosphate buffer $(0 \cdot 1 \mathrm{~m}, \mathrm{pH} 7 \cdot 0)$. A positive control containing $2 \mathrm{~g}$ Synergy $1{ }^{\circledR}$ (inulin enriched with oligofructose; ORAFTI) and a negative control (blank: fermentation buffer only) were included. Pre-digestion was simulated by incubation with $\alpha$-amylase (Sigma A-0521; $17.36 \mu$ from a 500 $\mathrm{U} / 500 \mu \mathrm{l}$ stock solution in $20 \mathrm{mM}-\mathrm{NaH}_{2} \mathrm{PO}_{4}$ buffer) for $5 \mathrm{~min}$ at $37^{\circ} \mathrm{C}$ (simulation of the mouth) and for $2 \mathrm{~h}$ with pepsin (Sigma P-7012) at $37^{\circ} \mathrm{C}(1.11 \mathrm{mg}$ in $0.94 \mathrm{ml} 20 \mathrm{~mm}-$ $\mathrm{HCl}$; $\mathrm{pH} 2 \cdot 0$; simulation of the stomach). In order to simulate the small intestine, the samples were incubated with an intestinal extract of pancreatin and oxgall (Sigma P-1750, FlukaSigma $70168,2.6 \mathrm{mg}$ and $5.0 \mathrm{mg}$, respectively in $5 \mathrm{ml}$ of 11 mm-bicarbonate buffer; $\mathrm{pH}$ 6.5) in a dialysis membrane (molecular weight cut-off: $1000 \mathrm{Da}$ ) under a semi-anaerobic condition at $37^{\circ} \mathrm{C}$ for $6 \mathrm{~h}$. Semi-anaerobic conditions were achieved by removing a part of the air in the fermentation bottles via a cannula at 0.5 bar for $1 \mathrm{~min}$ and subsequently injecting a fermentation gas mixture $\left(86 \% \mathrm{~N}_{2}, 10 \% \mathrm{CO}_{2}\right.$ and $\left.4 \% \mathrm{H}_{2}\right)$ at $0 \cdot 8$ bar for $1 \mathrm{~min}$ for seven cycles repeated ( $15 \mathrm{~min}$ ) according to Stein et $a l^{(41)}$.

For the in vitro fermentation, the suspensions were mixed to equal parts with human faecal slurries (approximately $25 \mathrm{ml}$ pooled suspension from three human donors) and fermented under anaerobic conditions for $24 \mathrm{~h}$ at $37^{\circ} \mathrm{C}$ and a starting $\mathrm{pH}$-value of 6.5 . Anaerobic conditions were achieved by gas exchange as described previously for $30 \mathrm{~min}$ (fourteen cycles repeated). The fermentation process was stopped by placing the suspensions on ice and the $\mathrm{pH}$ was measured.

\section{Preparation of nut fermentation supernatants}

fs were obtained by centrifugation of the faeces suspension for $30 \mathrm{~min}$ at $4200 \mathrm{~g}$. The supernatant fractions were centrifuged again for $15 \mathrm{~min}$ at $4200 \mathrm{~g}$. The fs from three different fermentations were pooled and centrifuged for $15 \mathrm{~min}$ at $16000 \mathrm{~g}$. All centrifugation steps were performed at $4^{\circ} \mathrm{C}$. Afterwards, the fs were sterilised by filtration (pore size $0.22 \mu \mathrm{m}$ ) to obtain the final fs for further investigations. Before the sterilised fs were used for the incubation of respective colon cells, they were diluted with cell-culture medium to reach a final concentration of $2 \cdot 5,5,10$ or $20 \%(\mathrm{v} / \mathrm{v})$.

\section{Cell line and culture conditions}

The human colon adenocarcinoma cell line HT29 (American Type Culture Collection no. HTB-38) was used for cell culture experiments in this study. The origin, properties and cell culture conditions of this cell line have been described previously ${ }^{(39)}$. In brief, the cells were grown in Dulbecco's modified Eagle's medium (Gibson BRL) supplemented with 10\% fetal calf serum. For cell culture experiments, HT29 cells were seeded in ninety-six-well plates (determination of cell growth) or in 
six-well plates (determination of genotoxic- and anti-genotoxic effects), respectively. The cells were grown for $24 \mathrm{~h}$ before incubation with the fs $(2 \cdot 5-20 \%)$. After incubation, the cells were used for different assays, as described next. Cells of passages 10-21 were used for the experiments.

\section{Analysis of characteristical constituents of the fermentation supernatant}

The fs were analysed considering SCFA, BA, tocopherol content, and also antioxidative capacity. Additionally, the antioxidant potential and tocopherol concentration of raw material (ground nuts) were determined.

To analyse the concentrations of SCFA by GC, the fs were mixed with an internal standard (iso-caproic acid in concentrated formic acid). In brief, $1 \mu$ l of the mixture was injected and SCFA were separated on a Zebron ${ }^{\mathrm{TM}}$ FFAP Capillary GC Column 15 m (Phenomenex, Inc.). Each measurement followed a defined temperature protocol $\left(105^{\circ} \mathrm{C} 1.5 \mathrm{~min} \rightarrow 35^{\circ} \mathrm{C} /\right.$ $\left.\min \rightarrow 170^{\circ} \mathrm{C} 2 \mathrm{~min}\right)$ as described elsewhere ${ }^{(42)}$.

The BA concentrations of the fs were investigated by tandem MS according to a previous published protocol ${ }^{(25,43)}$. Briefly, the fs were diluted (1:10 in fermentation buffer) and solid phase extraction was carried out using 101 sorbent cartridges (Separtis) and cholic acid $-d_{4}$ as an internal standard. The tested BA were cholic acid, lithocholic acid, desoxycholic acid (DCA), dihydroxycholic acid, ursodesoxycholic acid, chenodesoxycholic acid, sodium taurochenodesoxycholic acid and sodium glycochenodesoxycholic acid. BA were eluted and separated on an RP-C8 column $(100 \times 4 \mathrm{~mm}$, $5 \mu \mathrm{m}$; MZ-Analysentechnik); and $10 \mathrm{~mm}$-ammonium acetate buffer ( $\mathrm{pH} 5.0$ ) was used as the mobile phase with eluant A (formic acid, 0.012\%) and eluant B (acetonitrile). The eluants were linearly changed from $70 \% \mathrm{~A}$ and $30 \% \mathrm{~B}$ to $30 \% \mathrm{~A}$ and $70 \% \mathrm{~B}$ within $38 \mathrm{~min}$, held for $10 \mathrm{~min}$ and finally changed to their original ratio. The determination of BA was performed with a tandem mass spectrometer API $4000^{\mathrm{TM}}$ (Applied Biosystems/MDS SCIEX), equipped with an ESI ionisation source operating in the negative mode at $-4.5 \mathrm{kV}$ at $450^{\circ} \mathrm{C}$. BA were quantified by external calibration in the multiple reaction monitoring (MRM) mode using the Analyst 1.4 software (Applied Biosystems/MDS SCIEX).

Tocopherol concentrations of the ground nuts and fs were measured by HPLC according to an established protocol ${ }^{(44)}$. Tocopherols were extracted with $n$-hexane, ethanol and tert-buthylmethylether and separated on a Knauer Europher 100 DIOL column $(250 \times 4.0 \mathrm{~mm}, 7 \mu \mathrm{m})$ with a mixture of $n$-hexane-tertbuthylmethylether $(98+2, \mathrm{v} / \mathrm{m})$ as the mobile phase. Tocopherol isomers were determined by fluorescence $\left(\lambda_{\text {ex }} 292 \mathrm{~nm}\right.$, $\lambda_{\mathrm{em}} 330 \mathrm{~nm}$ ) and quantified via an external standard curve.

\section{Analysis of the antioxidant potential}

To analyse the antioxidant capacity of the raw material (ground nuts) and the fs, it was necessary to use different extraction methods. Considering that the antioxidant substances could be lipo- or hydrophilic, we used the trolox equivalent antioxidant capacity (TEAC)- and the 1,1-diphenyl-2-picrylhydrazyl
(DPPH)-assay. The TEAC-test for foodstuffs with lipophilic antioxidants was used for the ground nuts after a slightly modified protocol ${ }^{(45)}$ of Miller et al. ${ }^{(46)}$. The ground nuts were extracted in $100 \mu$ l hexane. ABTS solution (2,2'-azino-bis (3ethylbenzothiazoline-6-sulfonic acid) in phosphate buffer) was then added. After centrifugation (30s), the extinction of the ABTS-nut extract was measured after 2 min with the V-530 spectrophotometer (Jasco). To determine the antioxidant potential considering lipophilic and hydrophilic antioxidants, the DPPH-test modified according to Liua et al. ${ }^{(47)}$ was used. Therefore, extraction of the ground nuts was done with ethanol and before measuring the extinction at $540 \mathrm{~nm}$ with the V-530 spectrophotometer (Jasco) DPPH solution was added. The fs as more hydrophilic mixtures were analysed with a TEAC-test for hydrophilic antioxidants after a protocol described previously ${ }^{(45,48)}$ with an extinction of $743 \mathrm{~nm}$.

\section{Determination of cell growth}

The 4',6-diamidino-2-phenylindol (DAPI) assay was used to examine the time- and dose-dependent effects of fs. HT29 cells were seeded in ninety-six-well plates and grown for $24 \mathrm{~h}$. After an additional 24, 48 or $72 \mathrm{~h}$ of incubation with the fs $(5-20 \%)$, the relative cell number was quantified using a protocol described previously ${ }^{(49)}$. After 30 min of cell incubation with the DNA intercalating fluorescent dye DAPI, the DNA content as a reflection of the remaining number of cells was detected by fluorimetric analysis (excitation $360 \mathrm{~nm}$; emission $465 \mathrm{~nm}$ ) in a microplate reader (Spectra Fluor Plus Tecan). The results were calculated on the basis of the medium control which was set to $100 \%$.

\section{Cell cycle analysis}

To analyse the influence of nut fs on the cell cycle, HT29 cells were seeded in six-well plates and grown for $24 \mathrm{~h}$. Afterwards, the cells were incubated with fs (5\%) for 24,48 and $72 \mathrm{~h}$, subsequently trypsinised and dissolved in PBS. After measuring the cell viabilities and cell number with a CASY-cell counter (CASY $^{\circledR}$ model TT; Roche Innovatis AG CASY ${ }^{\circledR}$ Technology), they were stained with NIM-DAPI (0.6\% Nondinet P40 and $10 \mu \mathrm{g} / \mathrm{l}$ DAPI dissolved in PBS). Then, $10 \mathrm{~min}$ later, the intercalated DAPI was quantified by flow cytometry, whereas counted cells were allocated to the phases of the cell cycle using cytometry analysis software (Cell Lab Quanta TM SC_MPL 1.0; Beckman Coulter) ${ }^{(25)}$.

\section{Determination of genotoxic and anti-genotoxic effects}

To determine the genotoxic/anti-genotoxic potential of the nut fs, the single-cell micro gel electrophoresis (comet assay) was used as has been described elsewhere ${ }^{(50,51)}$. To identify the genotoxic effects of the nut fs, HT29 cells were seeded in six-well plates and $24 \mathrm{~h}$ later they were incubated with different concentrations ( 2.5 and $5 \%$ ) of the nut fs or controls for an additional 1 or $24 \mathrm{~h}$. Subsequently, the cells were washed, trypsinised and dissolved in PBS. $\mathrm{H}_{2} \mathrm{O}_{2}(75 \mu \mathrm{M}$, $5 \mathrm{~min}$ at $4^{\circ} \mathrm{C}$ ) and PBS were used as positive and negative 
controls, respectively. To analyse the anti-genotoxic effects, HT29 cells were grown for $24 \mathrm{~h}$, incubated for $15 \mathrm{~min}$ (short term, co-incubation with $\mathrm{H}_{2} \mathrm{O}_{2}$ ) and $24 \mathrm{~h}$ (long term) with nut fs and challenged with $75 \mu \mathrm{M}-\mathrm{H}_{2} \mathrm{O}_{2}$ for $15 \mathrm{~min}$ at $37^{\circ} \mathrm{C}$ as has been described elsewhere ${ }^{(52)}$. Viabilities and cell numbers were determined with a CASY-cell counter (CASY ${ }^{\circledR}$ model TT; Roche Innovatis AG CASY ${ }^{\circledR}$ Technology) and a defined cell number of $0.4 \times 10^{6}$ cells were mixed with $75 \mu \mathrm{l} 0.7 \%$ lowmelting agarose (Biozym) dissolved in PBS and distributed onto microscopic slides coated with $0.5 \%$ normal-melting agarose (Biozym). Further steps were carried out as described elsewhere ${ }^{(38,52)}$. DNA was stained with the fluorescent dye SYBR $^{\circledR}$ Green (Sigma Aldrich Chemie GmbH) and detected with a fluorescence microscope (ZEISS Axiostar plus; Carl Zeiss Jena $\mathrm{GmbH}$ ) using an image analysis system (Comet Assay IV, Perceptive Instruments). The degree of DNA damage correlates with the fluorescence in the tail ( $\%$ tail intensity). For each concentration, means of sixty cells were the basis for calculating the effect in one experiment.

\section{Statistical evaluation}

Means and standard deviations were calculated from at least three independent experiments. Statistical differences were analysed by one- or two-way ANOVA, including Bonferroni post-test using GraphPad Prism ${ }^{\circledR}$ version 5 for Windows (GraphPad software). The one-way ANOVA was done to define differences within one group if more than two concentrations were used. The two-way ANOVA was used to define differences between two groups if more than two concentrations were used. Otherwise, the comparison of two groups was done using Student's $t$ test.

\section{Results}

\section{Analysis of $\mathrm{pH}$}

The in vitro fermentation of all nuts resulted in a significantly decreased $\mathrm{pH}$ value ( $\mathrm{pH} 6.12$ (SD 0.09)) compared with the fs blank (pH 6.53 (SD 0.05)). The positive control Synergy $1^{\circledR}$ showed the strongest effect ( $\mathrm{pH} 4.58$ (SD 0.26)). The lowered
$\mathrm{pH}$ is a first indication of the generation of acidic metabolites by in vitro fermentation (Table 1).

\section{Analysis of characteristical constituents of the fermentation supernatant}

Analysis of SCFA. Table 1 demonstrates that the total amounts of SCFA in the nut fs were explicitly higher (67.83$85.93 \mathrm{~mm})$ than in the blank control $(32 \cdot 15 \mathrm{~mm})$. More importantly, the molar ratio of acetate-propionate-butyrate shifted from 56.94:21.31:21.75 in the blank to an average of $44 \cdot 50: 20 \cdot 86: 34 \cdot 64$ in the nut samples. Thereby, the ratio of acetate was decreased in favour of the highly bioactive SCFA butyrate. No major differences between the nut varieties were found. Fermentation of Synergy $1{ }^{\circledR}$ resulted in the highest amount of SCFA (112.00 mm).

Analysis of bile acids. Only three of eight investigated BA were detectable in noteworthy quantities. Hence, concentrations of the primary BA cholic acid as well as the secondary BA DCA and lithocholic acid are proven in the nut fs (Table 1). The fermentation of all nut varieties lowered especially the DCA concentrations $(8.20-88.65 \mathrm{~mm})$ in comparison to fs blank $(125.05 \mu \mathrm{M})$. Almond-, walnut- and pistachios fs showed comparable DCA concentrations. The lowest concentrations of DCA were detectable in the fs of hazelnuts $(16.48 \mu \mathrm{m})$ and macadamias $(8.20 \mu \mathrm{M})$. These very low concentrations of DCA were even lower than the amount found in Synergy $1^{\circledR}$ fs. A further notable finding was that cholic acid was only detectable in the fs of Synergy $1{ }^{\circledR}$ but hardly in that of nuts.

Analysis of tocopherol concentrations. To compare the tocopherol concentrations in nuts before and after in vitro fermentation, ground nuts and the fs were analysed. Table 2 shows that $\alpha$-tocopherol was the main form found in almonds and hazelnuts. The total amounts of tocopherol in these nut varieties were $16.5 \mathrm{mg} / 100 \mathrm{~g}$ and $25.2 \mathrm{mg} / 100 \mathrm{~g}$. In contrast, the amounts of tocopherol in pistachios $(9.8 \mathrm{mg} / 100 \mathrm{~g})$ and walnuts $(9.3 \mathrm{mg} / 100 \mathrm{~g})$ were considerably lower. In macadamias, only $\alpha$-tocotrienol was found at a concentration of $1.4 \mathrm{mg} /$ $100 \mathrm{~g}$. On the other hand, only in the fs of hazelnuts and almonds, respectively, rather low amounts of $\alpha$-tocopherol, $\alpha$ tocotrienol and $\beta$-tocotrienol were detectable (data not shown).

Table 1. Comparison of $\mathrm{pH}$, SCFA concentrations, ratio of main SCFA (acetate-propionate-butyrate) as well as the concentration of bile acids (BA) in fermentation supernatant ( $\mathrm{fs}$ ) after in vitro fermentation of different nuts, blank (fermentation buffer only as negative control) and Synergy $1^{\circledR}$ (as positive control)

(Mean values and standard deviations)

\begin{tabular}{|c|c|c|c|c|c|c|c|c|c|c|}
\hline \multirow[b]{2}{*}{ fs } & \multicolumn{2}{|c|}{$\mathrm{pH}$} & \multirow[b]{2}{*}{ Total SCFA (mmol/l) } & \multicolumn{3}{|c|}{ Main SCFA $(\mathrm{mmol} / \mathrm{l}) \dagger$} & \multirow[b]{2}{*}{ Ratio of main SCFA \% } & \multicolumn{3}{|c|}{$\mathrm{BA}(\mu \mathrm{M}) \dagger$} \\
\hline & Mean & SD & & Acetate & Propionate & Butyrate & & $\mathrm{CA}$ & DCA & LCA \\
\hline Blank & 6.53 & 0.05 & $32 \cdot 15$ & $16 \cdot 26$ & $6 \cdot 08$ & $6 \cdot 21$ & $56 \cdot 94: 21 \cdot 31: 21 \cdot 75$ & 1.59 & $125 \cdot 08$ & $7 \cdot 71$ \\
\hline Synergy $1^{\circledR}$ & $4.58^{\star *}$ & 0.26 & $112 \cdot 00$ & $70 \cdot 69$ & 8.79 & $28 \cdot 71$ & $65 \cdot 34: 8 \cdot 13: 26 \cdot 53$ & $14 \cdot 07$ & $23 \cdot 82$ & $7 \cdot 67$ \\
\hline Hazelnuts & $6 \cdot 10^{\star *}$ & 0.02 & 67.83 & $27 \cdot 42$ & $12 \cdot 35$ & $20 \cdot 51$ & $45 \cdot 48: 20 \cdot 49: 34 \cdot 03$ & n.d. & $16 \cdot 48$ & $5 \cdot 61$ \\
\hline Macadamias & $6 \cdot 14^{*}$ & 0.14 & 71.47 & 28.58 & $13 \cdot 10$ & 22.65 & $44 \cdot 43: 20 \cdot 37: 35 \cdot 21$ & n.d. & $8 \cdot 20$ & 5.49 \\
\hline Almonds & $6 \cdot 09^{\star \star}$ & 0.05 & 85.93 & 35.93 & $16 \cdot 54$ & 24.41 & $46 \cdot 74: 21 \cdot 51: 31 \cdot 76$ & n.d. & $68 \cdot 27$ & $6 \cdot 27$ \\
\hline Pistachios & $6 \cdot 03^{\star *}$ & 0.07 & $70 \cdot 83$ & $27 \cdot 87$ & $12 \cdot 78$ & 23.87 & $43 \cdot 20: 19 \cdot 81: 37 \cdot 00$ & 0.48 & 81.01 & $7 \cdot 39$ \\
\hline Walnuts & $6 \cdot 26^{\star}$ & 0.04 & $72 \cdot 19$ & $27 \cdot 40$ & $14 \cdot 22$ & 22.62 & $42 \cdot 65: 22 \cdot 14: 35 \cdot 21$ & 0.38 & 88.65 & 7.49 \\
\hline
\end{tabular}

CA, cholic acid; DCA, desoxycholic acid; LCA, lithocholic acid; n.d., not detectable.

Mean values were significantly different from those of the fs blank: * $P<0.05,{ }^{\star \star} P<0.01$ ( $t$ test)

$\dagger$ Three different fermentations were pooled, only one determination in triplicate could be conducted. A statistical analysis was therefore not possible. 
Table 2. Overview of the analysed vitamin E forms of different nut varieties

\begin{tabular}{|c|c|c|c|c|c|c|c|c|}
\hline \multirow[b]{2}{*}{ Nuts } & \multicolumn{8}{|c|}{ Concentration $(\mathrm{mg} / 100 \mathrm{~g}) \dagger$} \\
\hline & Total tocopherol & $\alpha$-Tocopherol & $\alpha$-Tocotrienol & $\beta$-Tocopherol & $\gamma$-Tocopherol & $\gamma$-Tocotrienol & $\delta$-Tocopherol & $\delta$-Tocotrienol \\
\hline Hazelnuts & $25 \cdot 2$ & 17.97 & n.d. & $1 \cdot 23$ & $5 \cdot 06$ & n.d. & 0.79 & 0.03 \\
\hline Macadamias & $1 \cdot 1$ & n.d. & 1.41 & n.d. & n.d. & n.d. & n.d. & n.d. \\
\hline Almonds & $16 \cdot 5$ & $14 \cdot 31$ & n.d. & 0.02 & $2 \cdot 70$ & n.d. & n.d. & n.d. \\
\hline Pistachios & $9 \cdot 8$ & n.d. & n.d. & n.d. & $7 \cdot 87$ & $0 \cdot 30$ & 1.59 & n.d. \\
\hline Walnuts & $9 \cdot 3$ & 0.26 & n.d. & n.d. & $7 \cdot 60$ & n.d. & 1.67 & n.d. \\
\hline
\end{tabular}

n.d., not detectable.

†Three different fermentations were pooled, only one determination in triplicate could be conducted. A statistical analysis was therefore not possible.

\section{Analysis of the antioxidant potential}

Using the TEAC and DPPH assays, it was possible to demonstrate (Fig. 1) that different natural nuts have a significant higher antioxidant capacity as the fibre source Synergy $1^{\circledR}$, which had no effects regarding either the hydrophilic or the lipophilic assay. While hazelnuts, almonds, pistachios and walnuts showed similar effects, macadamias represented a nearly $50 \%$ lower antioxidant potential.

The antioxidant capacity of fermented nuts was measured with the TEAC assay. Apart from macadamias, all nut fs at least tended to show a higher antioxidant capacity than the blank control (Fig. 2). It is noteworthy that walnut fs had the strongest effect with an about 2.5-fold higher antioxidant capacity than the blank control. In comparison to the blank control, fermentation of Synergy $1{ }^{\circledR}$ had no additional effect.

\section{Determination of cell growth}

The fermented nut samples were used to analyse their effect on cell growth of HT29 adenocarcinoma cells. Treatment of cells with the fs affected the cell number in a time- and dose-dependent manner. No effects were observed after an incubation of $24 \mathrm{~h}$ (data not shown). However, the cell number was significantly reduced after the incubation of HT29 cells with $20 \%$ of the fs of hazelnuts and almonds for $48 \mathrm{~h}$ compared to the medium control (Fig. 3). A significant decrease in cell number was also seen for the fs Synergy $1^{\circledR}$. After $72 \mathrm{~h}$ incubation, apart from pistachios all fs of nuts and Synergy $1{ }^{\circledR}$ were able to decrease the cell number in comparison to the medium control (Fig. 4), but without an additional effect to the blank. Significant results were already seen for
$5 \%$ of the almond fs. Surprisingly, low concentrations of pistachio fs resulted in a slight increase in cell growth.

\section{Cell cycle analysis}

Cell cycle distribution was determined to analyse the antiproliferative effects of the fermented nuts on HT29 cells. However, none of the fs $(5 \%)$ were able to modulate the cell cycle progression after short- $(24 \mathrm{~h})$ or longer incubation times (48, $72 \mathrm{~h}$ ) (data not shown).

\section{Determination of genotoxic and anti-genotoxic effects}

The treatment of HT29 cells with fs of different nut samples (2.5-10\%) for 1 and $24 \mathrm{~h}$ (data not shown) did not induce DNA damage as reflected by tail intensities comparable to the negative control. Therefore, fermented nuts are considered to be not genotoxic in HT29 cells.

To analyse whether treatment with fermented nuts caused an improved protection against oxidative stress, HT29 cells were incubated for $15 \mathrm{~min}$ as well as $24 \mathrm{~h}$ with the test substances and challenged with $\mathrm{H}_{2} \mathrm{O}_{2}$ to induce DNA damage. No cytotoxic impact of either substance was detected at the applied concentrations and times (data not shown). Treatment of HT29 cells for $24 \mathrm{~h}$ did not result in reduced levels of DNA damage (data not shown). Co-incubation with the fs of nuts tended to reduce the levels of $\mathrm{H}_{2} \mathrm{O}_{2}$-induced DNA damage after $15 \mathrm{~min}$ (Fig. 5) in comparison to the positive control. In particular, the treatment with the walnut fs resulted in a significantly reduced level of DNA damage compared to the positive control and the fs of blank and Synergy $1^{\circledR}$.

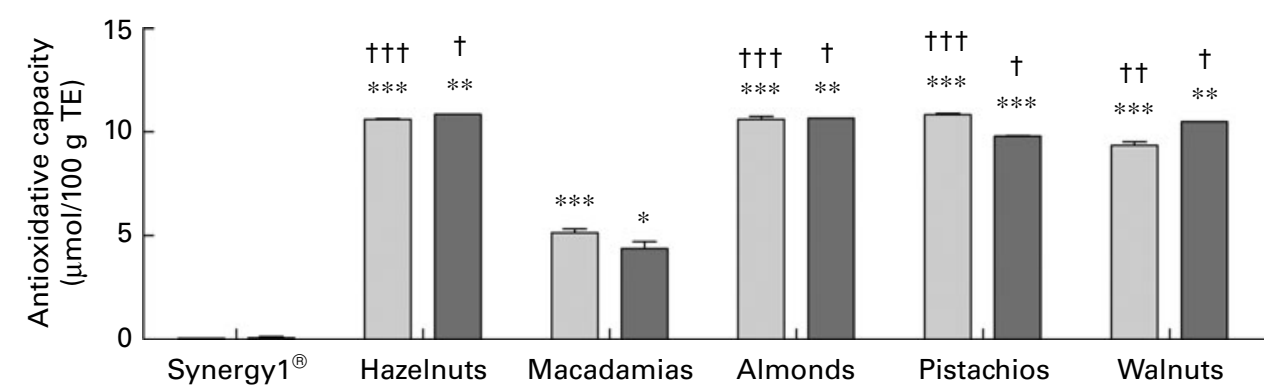

Fig. 1. Antioxidant potential of natural nuts analysed with $\square$ trolox equivalent antioxidant capacity- and $\square$ 1,1-diphenyl-2-picrylhydrazyl-assay. Values are means, with standard deviations represented by vertical bars $(n 3)$. Student's $t$ test was used to calculate differences from Synergy $1{ }^{\circledR}\left({ }^{\star} P<0 \cdot 05\right.$, ${ }^{\star \star} P<0.01$, $\left.{ }^{\star \star \star} P<0.001\right)$ and from macadamia ( $P<0.05$, $† \uparrow P<0.01$, $\uparrow \dagger \uparrow P<0.001)$. TE, tocopherol equivalent. 


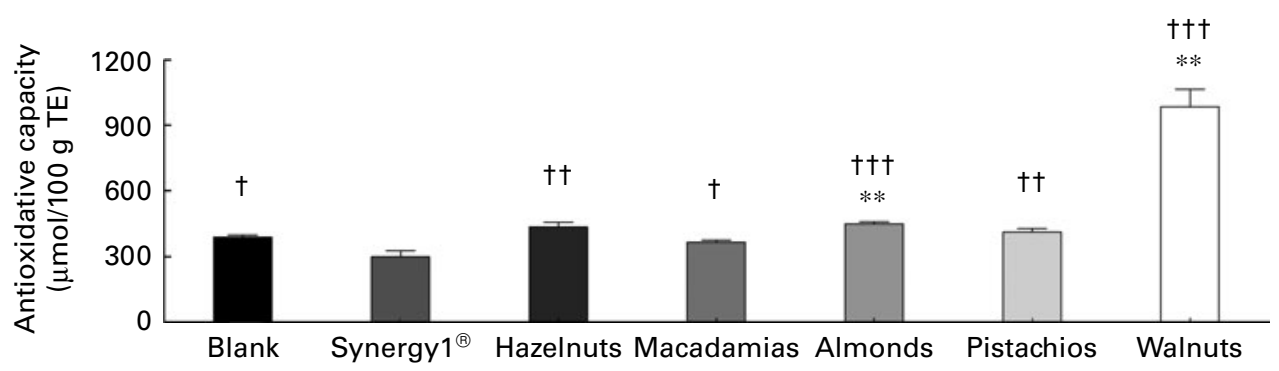

Fig. 2. Antioxidant capacity of nut fermentation supernatant determined with hydrophilic trolox equivalent antioxidant capacity-assay. Values are means, with standard deviations represented by vertical bars $(n 3)$. Student's $t$ test was used to calculate the differences from blank $\left.{ }^{\star \star} P<0.01\right)$ and from Synergy ${ }^{\circledR}(\dagger P<0.05$,

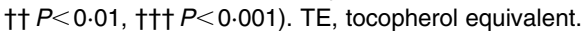

\section{Discussion}

Numerous health-promoting effects were attributed to the consumption of nuts ${ }^{(53)}$. These effects resulted from special ingredients, e.g. unsaturated fatty acids which are responsible for lower cholesterol levels and protection against CVD. However, nuts also contain antioxidant compounds (e.g. tocopherols, polyphenols) and health-promoting $\mathrm{DF}^{(4)}$. The consumption of DF might be associated with a reduced risk for developing colorectal cancer, one of the most common types of cancer in industrialised countries ${ }^{(36)}$. Despite this, a recent national survey showed that in Germany only $2 \mathrm{~g}$ of nuts were consumed per day ${ }^{(2,54)}$. Our knowledge about the positive effects of nuts results almost from human intervention trials and is based on chemical analysis of nut ingredients. So far there are no experimental studies available that explain the mechanism of action in the human gut. Hence, the aim of this project was to investigate the potential health-promoting effects of fermented nuts (hazelnuts, macadamias, almonds, pistachios, walnuts) using the human colon carcinoma cell line HT29.

In vitro fermentation of nuts resulted in an increased level of chemopreventive SCFA. Various studies showed the main faecal SCFA acetate, propionate and butyrate in a ratio of $60: 20: 20^{(55)}$. The ratio of fs blank of $56 \cdot 94: 21 \cdot 31: 21 \cdot 75$ was almost identical and confirms the comparability to physiological in vivo conditions. Fermentation of DF (Synergy $1{ }^{\circledR}$ and nuts) resulted in an increased level of SCFA and shifted the ratio to a higher level of butyrate. This is in line with former studies ${ }^{(25,56)}$ investigating the effect of different fibre sources on SCFA production. It is notable that all nut varieties showed a comparable influence on the concentration of
SCFA $(67 \cdot 83-85.93 \mathrm{mmol} / \mathrm{l})$ and the butyrate content (20.51$24.41 \mathrm{mmol} / \mathrm{l})$. The increased SCFA level resulted in a significantly reduced $\mathrm{pH}$ value of the fs. This might affect the gut microflora by a growth benefit of health-promoting lactobacilli and bifidobacteria ${ }^{(28-30,32)}$. BA were metabolised during the gut fermentation (7- $\alpha$-dehydroxylase activity of bacteria) and could be a risk factor for developing colon cancer, because high amounts of secondary BA are associated with tumourpromoting effects ${ }^{(57)}$. The presented results show that fermentation of nuts lowered the concentration of the secondary BA DCA compared to fs blank control. Thereby, hazelnuts and macadamias were more effective than the fs of the pure fibre source Synergy $1{ }^{\circledR}$. One reason for this protective effect might be the lower $\mathrm{pH}$ value in these fs which reduces the activity of converting enzymes and increases bacteria strains which are able to bind BA, as has been discussed elsewhere ${ }^{(25)}$. Furthermore, DF are able to bind BA directly ${ }^{(58)}$.

Another mechanism by which nut ingredients (e.g. tocopherols and secondary plant products like polyphenols and flavonoids) could exhibit chemopreventive effects is the prevention of oxidative DNA damage ${ }^{(59)}$. The present study confirmed that all the nut varieties used are an important source of vitamin $\mathrm{E}$, with substantial differences between the nuts. High tocopherol concentrations were found in almonds and hazelnuts (total tocopherol $16 \cdot 5 / 25 \cdot 2 \mathrm{mg}$ per $100 \mathrm{~g}$ ). Total tocopherol concentrations of pistachios and walnuts were considerably lower (approximately $9 \mathrm{mg} / 100 \mathrm{~g}$ ). Our results are in line with literature data which also concur that macadamias contain only low amounts of vitamin $\mathrm{E}$ and only in the form of $\alpha$-tocotrienol ${ }^{(4)}$.

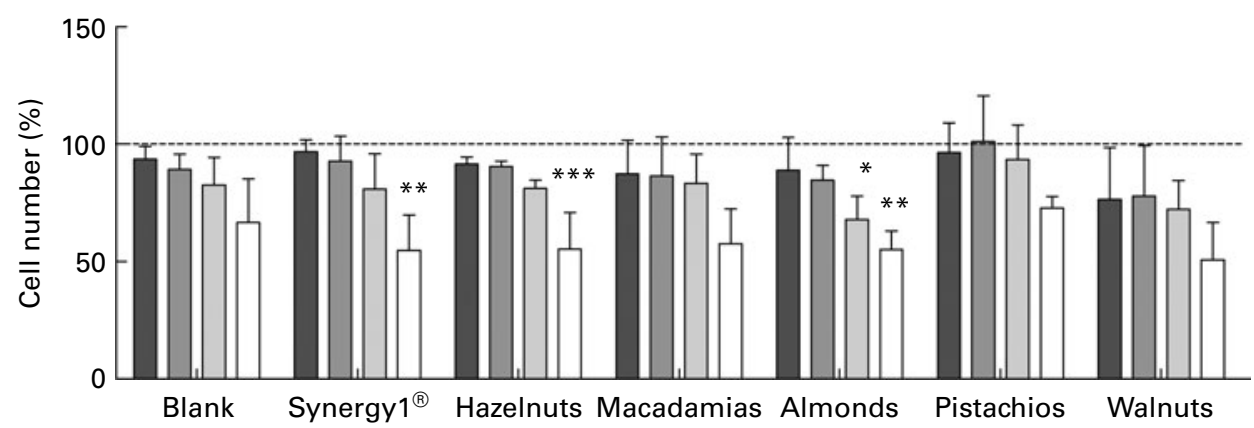

Fig. 3. Effects of nut fermentation supernatant (fs) $(2.5 \square, 5 \square, 10 \square, 20 \% \square)$ on growth of HT29 cells after $48 \mathrm{~h}$ incubation obtained by $4^{\prime}, 6$-diamidino-2-phenylindol-assay on the basis of the medium control which was set $100 \%$ (dashed line). Values are means, with standard deviations represented by vertical bars ( $n 3$ ). Statistical variance was analysed with one-way ANOVA/Bonferroni post-test, all fs $v$. medium control $\left({ }^{*} P<0.05,{ }^{\star *} P<0.01,{ }^{\star \star *} P<0.001\right)$. 




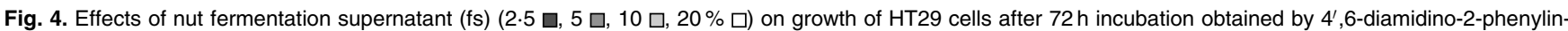
dol-assay on the basis of the medium control which was set $100 \%$ (dashed line). Values are means, with standard deviations represented by vertical bars $(n 3)$. Statistical variance was analysed with one-way ANOVA/Bonferroni post-test, all fs $v$. medium control $\left({ }^{\star} P<0.05,{ }^{\star \star} P<0.01,{ }^{\star \star \star} P<0.001\right)$ and two-way ANOVA/Bonferroni post-test, all fs $v$. blank ( $†$ P $<0.01$, $\dagger \dagger \dagger P<0.001)$.

Alasalvar et $a l^{(15)}$ reported about the high antioxidant capacity of hazelnuts, which is due to their high content of phytochemicals. We were able to confirm this statement and disclosed high antioxidant capacities of almost all nut varieties investigated in our present study. Furthermore, for the first time we demonstrated that fs of nuts had an antioxidant capacity, much higher than ground nuts. Particularly, walnut fs showed considerably higher effects than the other fs, maybe as a result of the high content of the bioactive ellagic acid ${ }^{(3)}$. The antioxidant activity of the Synergy $1^{\circledR}$ fs could be caused by the added faeces suspension. This reflects that not only the ingredients of nuts but also so far unidentified metabolites of the faeces inoculum have antioxidant effects and act synergistically with nut phytochemicals. Which and how much phytochemicals are really bioavailable after digestion is currently not clarified. Furthermore, since information about the complete phytochemical profile of nuts is lacking, further research is necessary ${ }^{(60,61)}$.

Effects on the cell number of transformed cells such as HT29 are thought to be a useful marker for secondary chemoprevention $^{(25)}$. The present study showed that the number of HT29 cells was efficiently diminished by all fs in a time- and dose-dependent manner. Surprisingly, pistachio fs showed a slight increase of cells, but only after $72 \mathrm{~h}$ of incubation. Further studies are necessary to disclose the ingredients responsible for this effect. The nut fs decreased cell growth similar to Synergy $1^{\circledR}$ and both were more effective compared to the medium control. This is due to the content of SCFA in fs. SCFA, especially butyrate, are biologically active and able to diminish the growth of cancer cells as shown recently by Borowicki et $a l^{(25)}$. Beside butyrate, also propionate demonstrated important anti-proliferative properties ${ }^{(24,26,34)}$. Additionally, it has been discussed that also the secondary BA DCA could reduce the cell number ${ }^{(38)}$, which could be the reason for the growth inhibitory potential of the control fs blank (DCA $125 \mu \mathrm{M}$ ) despite the low amount of SCFA of only $32 \mathrm{mmol} / \mathrm{l}$ and the missing significant difference of the nut fs. Thus, the growth inhibiting effect of the fs is probably not only due to the butyrate content. It may be the result of the additional activities of different partly unidentified fermentation metabolites, ellagic $\operatorname{acid}^{(62)}$ and/or synergistic effects with other SCFA like propionate. To get more insights into the mechanism which could be responsible for the effects on cell growth, the impact of fs on the cell cycle was also investigated. However, cell cycle modulation effects could not be detected. While butyrate in concentrations over $5 \mathrm{~mm}$

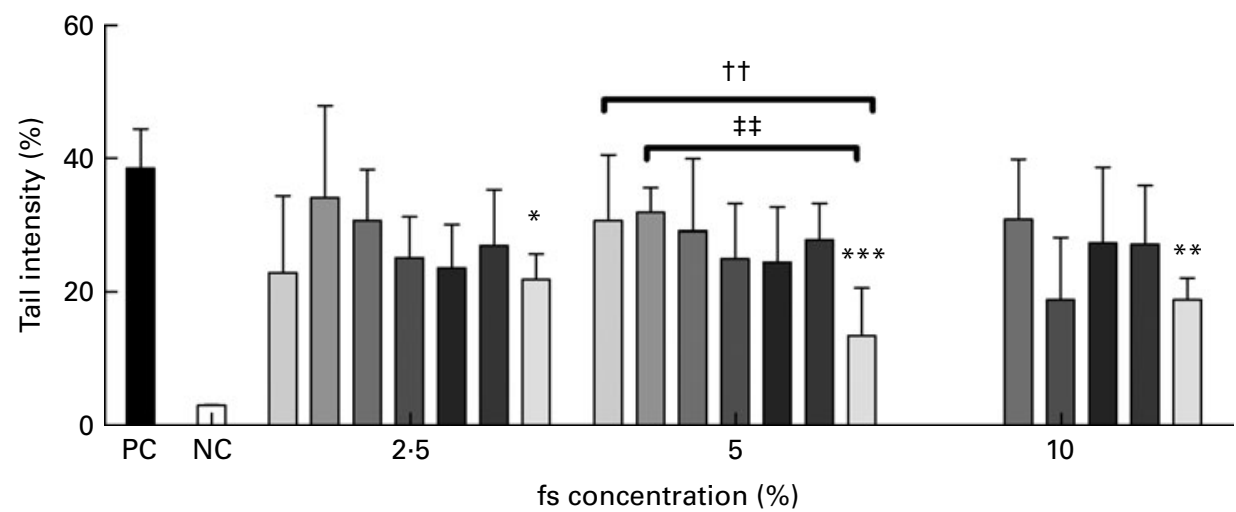

Fig. 5. Anti-genotoxic effects of nut fermentation supernatant (fs) (positive control (PC) $75 \mu \mathrm{M}$-hydrogen peroxide $\mathbf{\square}$; negative control (NC) $\square$, medium incubated cells treated with PBS; blank $\square$; Synergy $1{ }^{\circledR} \square$; hazelnuts $\square$; macadamias $\square$; almonds $\square$; pistachios $\square$; walnuts $\square$ ) in concentrations of $2.5-10 \%$ after 15 min incubation of HT29 cells with nut fs and co-incubation with hydrogen peroxide analysed with comet assay. Values are means, with standard deviations represented by vertical bars $(n 3)$. Statistical variance was analysed with one-way ANOVA/Bonferroni post-test, all fs $v$. positive control ( ${ }^{\star} P<0.05$, ${ }^{\star \star} P<0.01$, $\left.{ }^{\star \star \star} P<0.001\right)$ and twoway ANOVA/Bonferroni post-test, all fs $v$. blank $(\dagger \dagger P<0.01)$ and two-way ANOVA/Bonferroni post-test, all fs $v$. Synergy $1^{\circledR}$ ( $\left.\ddagger \ddagger P<0.01\right)$. 
has been shown to inhibit cell proliferation by arresting cells in the G0/G1 phase of the cell cycle, lower concentrations did not modulate the cell cycle progression ${ }^{(25,63)}$. The effective dose of butyrate in 5\% fs was too low (only between 1 and $1.2 \mathrm{~mm})$ to stimulate cell cycling modulation effects. In contrast, complex fs of wheat aleurone containing more than 5 mm-butyrate were able to arrest the cell cycle ${ }^{(64)}$.

In addition to the analysis of growth inhibition, the genotoxic and anti-genotoxic potential of fermented nuts, as a relevant marker for primary chemoprevention, were investigated for the first time. All fs of nuts and also the blank fs tended to prevent oxidative damage induced by $\mathrm{H}_{2} \mathrm{O}_{2}$. The fermented nuts showed a higher anti-genotoxic potential compared to Synergy $1{ }^{\circledR}$, but only the fs of walnuts indicated a significant reduction of the formation of oxidative DNA damage caused by $\mathrm{H}_{2} \mathrm{O}_{2}$. One reason for the anti-genotoxic effects of the fs walnut could be their high content of phenolic compounds ${ }^{(65)}$ and the resulting prominent antioxidant potential. Walnut phenolics are reported to display strong antioxidant and free-radicalscavenging capacities ${ }^{(66)}$. This could be also shown by the present study. Anti-genotoxicity can be the result of direct antioxidant activities ${ }^{(40,67)}$ and/or modification of DNA repair mechanisms and/or modulation of mRNA expression and activity of biotransformation and detoxification enzymes ${ }^{(40)}$. Given that a long-term incubation ( $24 \mathrm{~h}$ ) did not show any protective effect, the measured reduction of DNA damage by nuts might be the result of direct quenching of reactive hydroxyl radicals and this could prevent the formation of mutated cells.

In conclusion, this is the first study which presents the chemopreventive effects (reduction of tumour-promoting DCA, rise in chemopreventive SCFA, protection against oxidative stress) of different nuts after in vitro digestion and fermentation, and shows the potential importance of nuts in the prevention of colon cancer.

\section{Acknowledgements}

We would like to thank Nucis e.V. Germany for funding and their cooperate companies (Blue Diamond Growers, Max Kiene GmbH, Turkish Hazelnut Promotion Group, Paramount Farms and Mariani Nut Company) for allocation of the nuts. We express our gratitude to Ines Wienecke for technical assistance. We also thank the staff members of the Department of Nutritional Physiology for their support to analyse SCFA, the Department of Human Nutrition, especially Ms Beate Laube; as well as the AG Bioactive Plant Ingredients, especially Lars Müller for the guidance to analyse the tocopherols and the antioxidant capacity. S. L. was responsible for the practical realisation of the project and writing of the manuscript. W. S. contributed to in vitro fermentation, comet assay and cell growth analysis and the correction of the manuscript. M. B. supported analytical experiments like vitamin $\mathrm{E}$ analysis and finally corrected the manuscript. M. G. and D. S. are project leaders and were responsible for coordination and organisation of the project. M. G. finally amended and approved this manuscript for being published. All authors read the paper and approved it for publication. The authors have no conflicts of interest.

\section{References}

1. USDA (2010) Dietary Guidelines for Americans, 7th ed. Washington, DC: US Government Printing Office.

2. Deutsche Gesellschaft für Ernährung e. V. Bonn (2008) Ernäbrungsbericht 2008 (Nutrition Report 2008). Meckenheim: DCM Druck Center Meckenheim GmbH.

3. Anderson KJ, Teuber SS, Gobeille A, et al. (2001) Walnut polyphenolics inhibit in vitro human plasma and LDL oxidation. J Nutr 131, 2837-2842.

4. Alasalvar C \& Shahidi F (2009) Tree Nuts - Composition, Phytochemicals and Health Effects. Boca Raton, FL: CRC Press.

5. Nash SD \& Westpfal M (2005) Cardiovascular benefits of nuts. Am J Cardiol 95, 963-965.

6. Hu FB, Stampfer MJ, Manson JE, et al. (1998) Frequent nut consumption and risk of coronary heart disease in women: prospective cohort study. BMJ 317, 1341-1345.

7. Marangoni F, Colombo C, Martiello A, et al. (2007) Levels of the $n$ - 3 fatty acid eicosapentaenoic acid in addition to those of alpha linolenic acid are significantly raised in blood lipids by the intake of four walnuts a day in humans. Nutr Metab Cardiovasc Dis 17, 457-461.

8. Griel AE, Cao Y, Bagshaw DD, et al. (2008) A macadamia nut-rich diet reduces total and LDL-cholesterol in mildly hypercholesterolemic men and women. J Nutr 138, 761-767.

9. Garg ML, Blake RJ, Wills RB, et al. (2007) Macadamia nut consumption modulates favourably risk factors for coronary artery disease in hypercholesterolemic subjects. Lipids $\mathbf{4 2}$, $583-587$.

10. Torabian S, Haddad E, Cordero-Macintyre Z, et al. (2010) Long-term walnut supplementation without dietary advice induces favorable serum lipid changes in free-living individuals. Eur J Clin Nutr 64, 274-279.

11. Banel DK \& Hu FB (2009) Effects of walnut consumption on blood lipids and other cardiovascular risk factors: a metaanalysis and systematic review. Am J Clin Nutr 90, 56-63.

12. Garcia-Lorda P, Megias RI \& Salas-Salvado J (2003) Nut consumption, body weight and insulin resistance. Eur J Clin Nutr 57, Suppl. 1, S8-S11.

13. Rajaram S \& Sabate J (2006) Nuts, body weight and insulin resistance. Br J Nutr 96, Suppl. 2, S79-S86.

14. Rainey C \& Nyguist L (1997) Nuts - nutrition and health benefits of daily use. Nutrition Today 32, 157-163.

15. Alasalvar C, Karamac M, Kosinska A, et al. (2009) Antioxidant activity of hazelnut skin phenolics. J Agric Food Chem 57, 4645-4650.

16. Dujardin U (2007) Nüsse in der gesunden Ernährung (Nuts in healthy diet). Ernährungsumschau 9, 554-556.

17. Coates AM \& Howe PR (2007) Edible nuts and metabolic health. Curr Opin Lipidol 18, 25-30.

18. Gray J (2006) Dietary Fibre - Definition, Analysis, Physiology \& Health, pp. 22-23. Brussels: International Life Sciences Institute Europe.

19. Cummings JH (2001) The effect of dietary fiber on fecal weight and composition. In CRC Handbook of Dietary Fiber in Human Nutrition, vol. 3, p. 183-252 [GA Spiller, editor]. Boca Raton, FL: CRC Press.

20. Bingham SA, Day NE, Luben R, et al. (2003) Dietary fibre in food and protection against colorectal cancer in the European Prospective Investigation into Cancer and Nutrition (EPIC): an observational study. Lancet 361, 1496-1501.

21. Davis PA \& Iwahashi CK (2001) Whole almonds and almond fractions reduce aberrant crypt foci in a rat model of colon carcinogenesis. Cancer Lett 165, 27-33. 
22. Jenab M, Ferrari P, Slimani N, et al. (2004) Association of nut and seed intake with colorectal cancer risk in the European Prospective Investigation into Cancer and Nutrition. Cancer Epidemiol Biomarkers Prev 13, 1595-1603.

23. Cummings JH, Pomare EW, Branch WJ, et al. (1987) Short chain fatty acids in human large intestine, portal, hepatic and venous blood. Gut 28, 1221-1227.

24. Beyer-Sehlmeyer G, Glei M, Hartmann E, et al. (2003) Butyrate is only one of several growth inhibitors produced during gut flora-mediated fermentation of dietary fibre sources. $\mathrm{BrJ}$ Nutr 90, 1057-1070.

25. Borowicki A, Stein K, Scharlau D, et al. (2010) Fermented wheat aleurone inhibits growth and induces apoptosis in human HT29 colon adenocarcinoma cells. Br J Nutr 103, 360-369.

26. Pool-Zobel BL \& Sauer J (2007) Overview of experimental data on reduction of colorectal cancer risk by inulin-type fructans. J Nutr 137, 2580S-2584S.

27. Sauer J, Richter KK \& Pool-Zobel BL (2007) Physiological concentrations of butyrate favorably modulate genes of oxidative and metabolic stress in primary human colon cells. J Nutr Biochem 18, 736-745.

28. Gibson GR \& Roberfroid MB (1995) Dietary modulation of the human colonic microbiota: introducing the concept of prebiotics. J Nutr 125, 1401-1412.

29. Mandalari G, Nueno-Palop C, Bisignano G, et al. (2008) Potential prebiotic properties of almond (Amygdalus communis L.) seeds. Appl Environ Microbiol 74, 4264-4270.

30. Gibson GR, Probert HM, Loo JV, et al. (2004) Dietary modulation of the human colonic microbiota: updating the concept of prebiotics. Nutr Res Rev 17, 259-275

31. Bernet MF, Brassart D, Neeser JR, et al. (1993) Adhesion of human bifidobacterial strains to cultured human intestinal epithelial cells and inhibition of enteropathogen-cell interactions. Appl Environ Microbiol 59, 4121-4128.

32. Gibson GR \& Wang X (1994) Regulatory effects of bifidobacteria on the growth of other colonic bacteria. J Appl Bacteriol 77, 412-420

33. Glei M, Habermann N, Osswald K, et al. (2005) Assessment of DNA damage and its modulation by dietary and genetic factors in smokers using the Comet assay: a biomarker model. Biomarkers 10, 203-217.

34. Rafter J, Govers M, Martel P, et al. (2004) PASSCLAIM - dietrelated cancer. Eur J Nutr 43, Suppl. 2, II47-II84.

35. Rafter J, Bennett M, Caderni G, et al. (2007) Dietary synbiotics reduce cancer risk factors in polypectomized and colon cancer patients. Am J Clin Nutr 85, 488-496.

36. Garcia M, Jemal A, Ward EM, et al. (2007) Global cancer facts \& figures. Am Cancer Soc 404, 320-3333.

37. Barry JL, Hoebler C, Macfarlane GT, et al. (1995) Estimation of the fermentability of dietary fibre in vitro: a European interlaboratory study. Br I Nutr 74, 303-322.

38. Glei M, Hofmann T, Kuster K, et al. (2006) Both wheat (Triticum aestivum) bran arabinoxylans and gut flora-mediated fermentation products protect human colon cells from genotoxic activities of 4-hydroxynonenal and hydrogen peroxide. J Agric Food Chem 54, 2088-2095.

39. Borowicki A, Stein K, Scharlau D, et al. (2010) Fermentation supernatants of wheat (Triticum aestivum L.) aleurone beneficially modulate cancer progression in human colon cells. J Agric Food Chem 58, 2001-2007.

40. Stein K, Borowicki A, Scharlau D, et al. (2010) Fermented wheat aleurone induces enzymes involved in detoxification of carcinogens and in antioxidative defence in human colon cells. Br J Nutr 104, 1101-1111.
41. Stein K, Borowicki A, Scharlau D, et al. (2011) Modification of an in vitro model simulating the whole digestive process to investigate cellular endpoints of chemoprevention. $\mathrm{Br} \mathrm{J}$ Nutr 105, 678-687.

42. Klein A, Friedrich U, Vogelsang H, et al. (2008) Lactobacillus acidophilus 74-2 and Bifidobacterium animalis subsp lactis DGCC 420 modulate unspecific cellular immune response in healthy adults. Eur J Clin Nutr 62, 584-593.

43. Burkard I, von Eckardstein A \& Rentsch KM (2005) Differentiated quantification of human bile acids in serum by high-performance liquid chromatography-tandem mass spectrometry. J Chromatogr B Analyt Technol Biomed Life Sci 826, 147-159.

44. Birringer M (2010) Analysis of vitamin E metabolites in biological specimen. Mol Nutr Food Res 54, 588-598.

45. Muller L, Theile K \& Bohm V (2010) In vitro antioxidant activity of tocopherols and tocotrienols and comparison of vitamin E concentration and lipophilic antioxidant capacity in human plasma. Mol Nutr Food Res 54, 731-742.

46. Miller NJ, Sampson J, Candeias LP, et al. (1996) Antioxidant activities of carotenes and xanthophylls. FEBS Lett $\mathbf{3 8 4}$ 240-242.

47. Liua D, Shi J, Ibarra AC, et al. (2008) The scavenging capacity and synergistic effects of lycopene, vitamin E, vitamin C, and beta-carotene mixtures on the DPPH free radical. $L W T-$ Food Sci Technol 41, 1344-1349.

48. Re R, Pellegrini N, Proteggente A, et al. (1999) Antioxidant activity applying an improved ABTS radical cation decolorization assay. Free Radic Biol Med 26, 1231-1237.

49. Klenow S, Pool-Zobel BL \& Glei M (2009) Influence of inorganic and organic iron compounds on parameters of cell growth and survival in human colon cells. Toxicol In vitro 23, 400-407.

50. Tice RR, Agurell E, Anderson D, et al. (2000) Single cell gel/ comet assay: guidelines for in vitro and in vivo genetic toxicology testing. Environ Mol Mutagen 35, 206-221.

51. Collins AR (2004) The comet assay for DNA damage and repair: principles, applications, and limitations. Mol Biotechnol 26, 249-261.

52. Glei M, Matuschek M, Steiner C, et al. (2003) Initial in vitro toxicity testing of functional foods rich in catechins and anthocyanins in human cells. Toxicol In vitro 17, 723-729.

53. Nash SD \& Nash DT (2008) Nuts as part of a healthy cardiovascular diet. Curr Atheroscler Rep 10, 529-535.

54. Bundesministerium für Ernährung, Landwirtschaft und Verbraucherschutz (2008) Nationale Verzehrsstudie II (National Nutritional Survey II). Karlsruhe: Max Rubner-Institut, Bundesforschungsarstalt für Ernährung und Lebensmittel.

55. Hamer HM, Jonkers D, Venema K, et al. (2008) Review Article: the role of butyrate on colonic function. Aliment Pharmacol Ther 27, 104-119.

56. McIntyre A, Gibson PR \& Young GP (1993) Butyrate production from dietary fibre and protection against large bowel cancer in a rat model. Gut 34, 386-391.

57. Tong JL, Ran ZH, Shen J, et al. (2008) Association between fecal bile acids and colorectal cancer: a meta-analysis of observational studies. Yonsei Med J 49, 792-803.

58. Zampa A, Silvi S, Fabiani R, et al. (2004) Effects of different digestible carbohydrates on bile acid metabolism and SCFA production by human gut micro-flora grown in an in vitro semi-continuous culture. Anaerobe 10, 19-26.

59. Byers T \& Perry G (1992) Dietary carotenes, vitamin C, and vitamin $\mathrm{E}$ as protective antioxidants in human cancers. Annu Rev Nutr 12, 139-159. 
60. Bolling BW, McKay DL \& Blumberg JB (2010) The phytochemical composition and antioxidant actions of tree nuts. Asia Pac J Clin Nutr 19, 117-123.

61. Chen CY \& Blumberg JB (2008) Phytochemical composition of nuts. Asia Pac J Clin Nutr 17, Suppl. 1, 329-332.

62. Fjaeraa C \& Nanberg E (2009) Effect of ellagic acid on proliferation, cell adhesion and apoptosis in SH-SY5Y human neuroblastoma cells. Biomed Pharmacother 63, 254-261.

63. Blottiere HM, Buecher B, Galmiche JP, et al. (2003) Molecular analysis of the effect of short-chain fatty acids on intestinal cell proliferation. Proc Nutr Soc 62, 101-106.

64. Borowicki A, Michelmann A, Stein K, et al. (2011) Fermented wheat aleurone enriched with probiotic strains LGG and
Bb12 modulates markers of tumor progression in human colon cells. Nutr Cancer 63, 151-160.

65. Pellegrini N, Serafini M, Salvatore S, et al. (2006) Total antioxidant capacity of spices, dried fruits, nuts, pulses, cereals and sweets consumed in Italy assessed by three different in vitro assays. Mol Nutr Food Res 50, 1030-1038.

66. Martinez ML, Labuckas DO, Lamarque AL, et al. (2010) Walnut (Juglans regia L.): genetic resources, chemistry, byproducts. J Sci Food Agric 90, 1959-1967.

67. Rosignoli P, Fabiani R, De Bartolomeo A, et al. (2001) Protective activity of butyrate on hydrogen peroxide-induced DNA damage in isolated human colonocytes and HT29 tumour cells. Carcinogenesis 22, 1675-1680. 